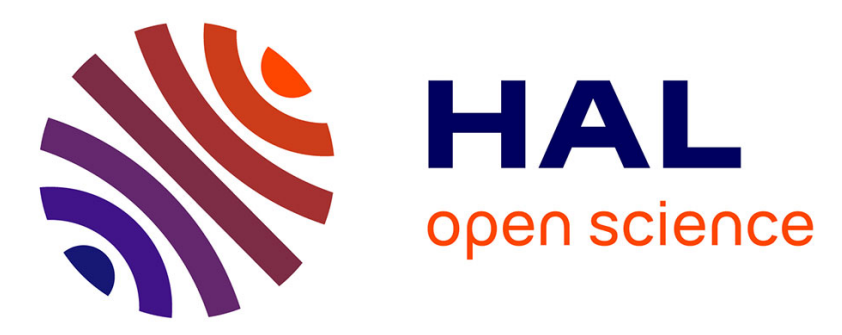

\title{
Superplastic behavior of rosin/beeswax blends at room temperature
}

\author{
Yves Gaillard, Marion Girard, Alain Burr, Evelyne Darque-Ceretti, Eric Felder
}

\section{To cite this version:}

Yves Gaillard, Marion Girard, Alain Burr, Evelyne Darque-Ceretti, Eric Felder. Superplastic behavior of rosin/beeswax blends at room temperature. Journal of Applied Polymer Science, 2012, 128 (5), pp.2713-2719. 10.1002/app.38333 . hal-01007351

\section{HAL Id: hal-01007351 https://hal.science/hal-01007351}

Submitted on 10 Mar 2018

HAL is a multi-disciplinary open access archive for the deposit and dissemination of scientific research documents, whether they are published or not. The documents may come from teaching and research institutions in France or abroad, or from public or private research centers.
L'archive ouverte pluridisciplinaire HAL, est destinée au dépôt et à la diffusion de documents scientifiques de niveau recherche, publiés ou non, émanant des établissements d'enseignement et de recherche français ou étrangers, des laboratoires publics ou privés. 


\title{
Superplastic Behavior of Rosin/Beeswax Blends at Room Temperature
}

\author{
Y. Gaillard, M. Girard, G. Monge, A. Burr, E. Darque Ceretti, E. Felder \\ Mines ParisTech., Centre de Mise en Forme des Matériaux, CNRS (Centre National de la Recherche Scientifique) \\ UMR (Unité Mixte de Recherche) 7635, BP 2071 rue Claude Daunesse 06904 Sophia Antipolis Cedex, France \\ Correspondence to: Y. Gaillard (E-mail: ygaillar@univ-fcomte.fr)
}

\begin{abstract}
Blends of rosin and beeswax were studied in terms of their thermal and mechanical behaviors. Their glass transition and $\alpha$ relaxation were both characterized, either by differential scanning calorimetry or by dynamic mechanical thermal analysis. In this study, we focused particularly on the impact of the microstructure on the mechanical properties, as studied by compression, shear, and nanoindentation tests. It is shown that at room temperature, these blends exhibited a viscous behavior in both the elastic and plastic regimes. From these measurements, a superplastic behavior was highlighted for blends with more than 60 wt $\%$ rosin. This superplastic behavior constitutes a real new potential in the mechanical reliability of adhesives based on rosin, which are more generally known for their very brittle behavior. As a result, it should open the way for the design of new shapes. (C) 2012 Wiley Periodicals, Inc. J. Appl. Polym. Sci. 000: 000-000, 2012
\end{abstract}

KEYWORDS: adhesives; biopolymers and renewable polymers; mechanical properties; viscosity and viscoelasticity

\section{INTRODUCTION}

Rosin is a biosourced material known as a very good tackifier because of its very low surface tension when mixed with the correct solvent. ${ }^{1,2}$ However, at room temperature (RT), it remains very brittle, having a toughness on the order of magnitude of tens of kilopascal meters ${ }^{0.5}$; this prohibits it from being included in most industrial applications in its pristine state. An amount of $90 \mathrm{wt} \%$ of rosin is formed by a complex blend of diterpenebased acids with the empirical formula $\mathrm{C}_{20} \mathrm{H}_{30} \mathrm{O}_{2}$. The other 10 wt $\%$ is a blend of esters, alcohols, aldehydes, and hydrocarbons. ${ }^{2}$ Numerous isomers belonging to three acids groups, namely, abietic, D-pimaric, and labdanic, compose the acidic fraction. ${ }^{3,4}$ The cohesion of rosin is ensured by weak bonds (van der Waals interactions and hydrogen bonding of the hydroxyl groups), ${ }^{5}$ but the structure remains amorphous as long as one of the isomers does not exceed $30 \%{ }^{6}$ The mechanical behavior of amorphous materials has been extensively studied, but no complete bibliography on the mechanical properties of rosins exist. Deformed close to their glass-transition temperature $\left(T_{g}\right)$ or under a high confining pressure, amorphous materials can present several deformation mechanisms of plasticity before fracture. ${ }^{7,8}$ At high a $T / T_{g}$ ratio (where $T$ is the temperature), amorphous materials exhibit a homogeneous Newtonian behavior. On the other hand, when the temperature is much lower than its $T_{g}$, shear bands are the seat of inhomogeneous deformations. Several deformation mechanisms have been proposed to explain this latest behavior. Indeed, silica glasses deform by permanent densification and sliding. ${ }^{9,10}$ On the contrary, the plastic deformations of metallic glasses are the result of a collective rearrangement of sheared clusters, that is, the socalled shear transformation zone proposed by Argon. ${ }^{1-13}$ A similar concept of sheared microdomains was also used by Perez ${ }^{14}$ for modeling the behavior of amorphous polymers.

One classical way to change the mechanical properties, or any other properties, of polymers consists of their blending with another material or by the incorporation of particles. ${ }^{15-17}$ This addition confers to the blends new combined properties and may modify in the same way $T_{g}$ and, so, the rheological properties. Depending on the miscibility of the two initial materials, this blend may result in a homogeneous material with a single glass transition or in a composite one with two glass transitions. In this article, we present a study of the thermomechanical behavior of melted rosin with a biosourced plasticizer, beeswax. ${ }^{18}$ If the major expected effect of this addition was evidently to improve the toughness of rosin, we show that it also revealed the superplastic behavior of some of the obtained blends, depending on the beeswax ratio. First, beeswax and rosin in their pristine states but also a blend of rosin and beeswax were studied by step-scan differential scanning calorimetry (DSC) to fully characterize their polymorphic transitions, glass transitions, and melting behavior. In particular, a close relationship between the rosin content and polymorphic transition temperatures of the crystalline part of the blend was confirmed. Then, the discussion is devoted to the viscoelastic properties studied by dynamic mechanical thermal 
analysis (DMTA). In particular, both the glass transition and polymorphic transitions of the different blends appeared to be closely related to their viscoelastic behavior. The last part focuses on the mechanical properties of the different blends. Particularly, the mechanical responses experienced under different solicitations of compression, shear, and nanoindentation are compared in terms of the strain rate sensitivity $(m)$. This revealed a viscoplastic behavior at RT that tended to superplasticity for blends containing more than $60 \mathrm{wt} \%$ rosin.

\section{EXPERIMENTAL}

Pristine rosin and beeswax were both purchased at a professional apiarist. ${ }^{19}$ They were melted at $100^{\circ} \mathrm{C}$. The complete melting procedure was described in a previous article. ${ }^{18}$ The blends are referenced as $X$ wt \%, where $X$ is the weight proportion of rosin.

DSC experiments were conducted on a PerkinElmer 8000 instrument. To obtain complete separation between the glass and polymorphic transitions, ${ }^{20-24}$ step-scan DSC experiments were performed. A first ramp was realized to reach complete melting, and then, the samples were cooled to $0^{\circ} \mathrm{C}$. The sample was then reheated to $80^{\circ} \mathrm{C}$. This was the second heating that is always presented as a step-scan DSC thermogram in this article. A step scan consists of incremental steps of temperature (in our case, steps of $1.5^{\circ} \mathrm{C}$ were applied). Each step was composed of a temperature ramp, where the temperature was increased very rapidly $\left(40^{\circ} \mathrm{C} / \mathrm{min}\right)$, followed by a plateau of $45 \mathrm{~s}$. In this way, the transitions coming from kinetic processes, such as phase transitions or melting, were separated from the total heat flow. This method is classically used to isolate phase transitions (detected during the plateau) from the glass transition (detected during the temperature steps). ${ }^{25-27}$ In the following, two curves are presented for each step scan. The heat flow curve was representative of the glass-transition phenomena, whereas the specific heat curve was representative of the total heat flow.

DMTA was performed on a Bohlin Instruments apparatus. Cylindrical samples $8 \mathrm{~mm}$ in diameter and $8 \mathrm{~mm}$ in height were tested in compression. A single temperature ramp between 0 and $60^{\circ} \mathrm{C}$ was applied at a rate of $0.3^{\circ} \mathrm{C} / \mathrm{min}$. Small deformations of $1.25 \times$ $10^{-4}$ were applied at different frequencies $(f s)$ between 0.1 and $10 \mathrm{~Hz}$. The storage modulus $\left(E^{\prime}\right)$, loss modulus, and also phase $\tan \delta$ were measured. $m$ was determined as follows:

$$
m_{\text {DMTA }}=\frac{d \log E^{\prime}}{d \log f}
$$

Compression and shear tests were performed with an electromechanical Erichsen apparatus at a temperature of $19.8 \pm 0.3^{\circ} \mathrm{C}$. Cylindrical samples $10 \mathrm{~mm}$ in height and $8 \mathrm{~mm}$ in diameter were compressed at constant velocities of $0.0015,0.01,0.1$, and $1 \mathrm{~mm} / \mathrm{s}$. Experiments at a constant strain rate were also conducted on 30 and $80 \mathrm{wt} \%$ blends. A release agent was used between the sample and the plates of the machine to reduce friction. The friction was considered negligible, and the tests were considered purely uniaxial. The true stress $(\sigma)$ and true strain $(\varepsilon)$ were defined classically as follows:

$$
\sigma=\frac{F}{S(t)}
$$

and

$$
\varepsilon=\ln \left(\frac{l(t)}{l_{0}}\right)
$$

where $F$ is the force applied to the sample, $l_{0}$ is the initial height of the sample, $l(t)$ is the height of the sample measured in situ during the compression test, and $S(t)$ is the in situ section of the sample, calculated from $l(t)$ with a volume conservation assumed. The length of the sample was recorded in situ with a digital camera at an image acquisition frequency of $33 \mathrm{~Hz}$.

Stress-strain curves were fitted with the G'Sell-Jonas $\operatorname{law}^{28}$ to determine the strain rate sensitivity of the different blends $\left(m_{\text {comp }}\right)$. The following law was used:

$$
\sigma=\sigma_{0} e^{h_{g} \varepsilon^{u}} \dot{\varepsilon}^{m}
$$

with

$$
m=m_{\mathrm{comp}}=\frac{d \log \sigma}{d \log \dot{\varepsilon}}
$$

where $\sigma_{0}$ is the strength, $\dot{\varepsilon}$ is the strain rate $\dot{l} / l$ (where $\dot{l}$ is $d l / d t$ ), $m$ is the power of $\dot{\varepsilon}$, and $h_{g}$ and $u$ are parameters characteristic of strain hardening.

Blends were also deformed by the shear way as follows. Two pieces of wood were assembled with an adhesive pad cast in an O-ring 2 $\mathrm{mm}$ in width and $10 \mathrm{~mm}$ in diameter. The wood was used to ensure good adhesion and transfer of the shear displacement to the adhesive pad. The global equivalent stress $(\tau)$ and global equivalent strain $(\gamma)$ curves were deduced from the following formulas:

$$
\begin{gathered}
\tau=\frac{F}{S} \\
\gamma=\frac{\Delta l}{e} \\
m_{\text {shear }}=\frac{d \log \tau}{d \log \dot{\gamma}}
\end{gathered}
$$

where $S$ is the section of the adhesive pad, $e$ is its thickness, $\Delta l$ is the relative displacement between the two pieces of wood along the loading direction, and $\dot{\gamma}=\Delta \dot{l} / e$ is the global equivalent strain rate.

Nanoindentation tests were realized with a Hysitron apparatus (Minneapolis, USA) with a Berkovich indenter having a tip defect about $200 \mathrm{~nm}$ in radius. The constant $\dot{h} / h$, where $h$ is the indentation depth and $\dot{h}$ is $d h / d t$, was applied. The calibration of the indenter shape was performed with fused silica as a reference. The strain rate sensitivity, as determined by the nanoindentation tests $\left(m_{\text {nano }}\right)$, was determined as follows:

$$
m_{\text {nano }}=\frac{\left.d \log F\right|_{h}}{d \log (\dot{h} / h)}
$$

where $\left.F\right|_{h}$ is the applied force at a constant penetration depth. 

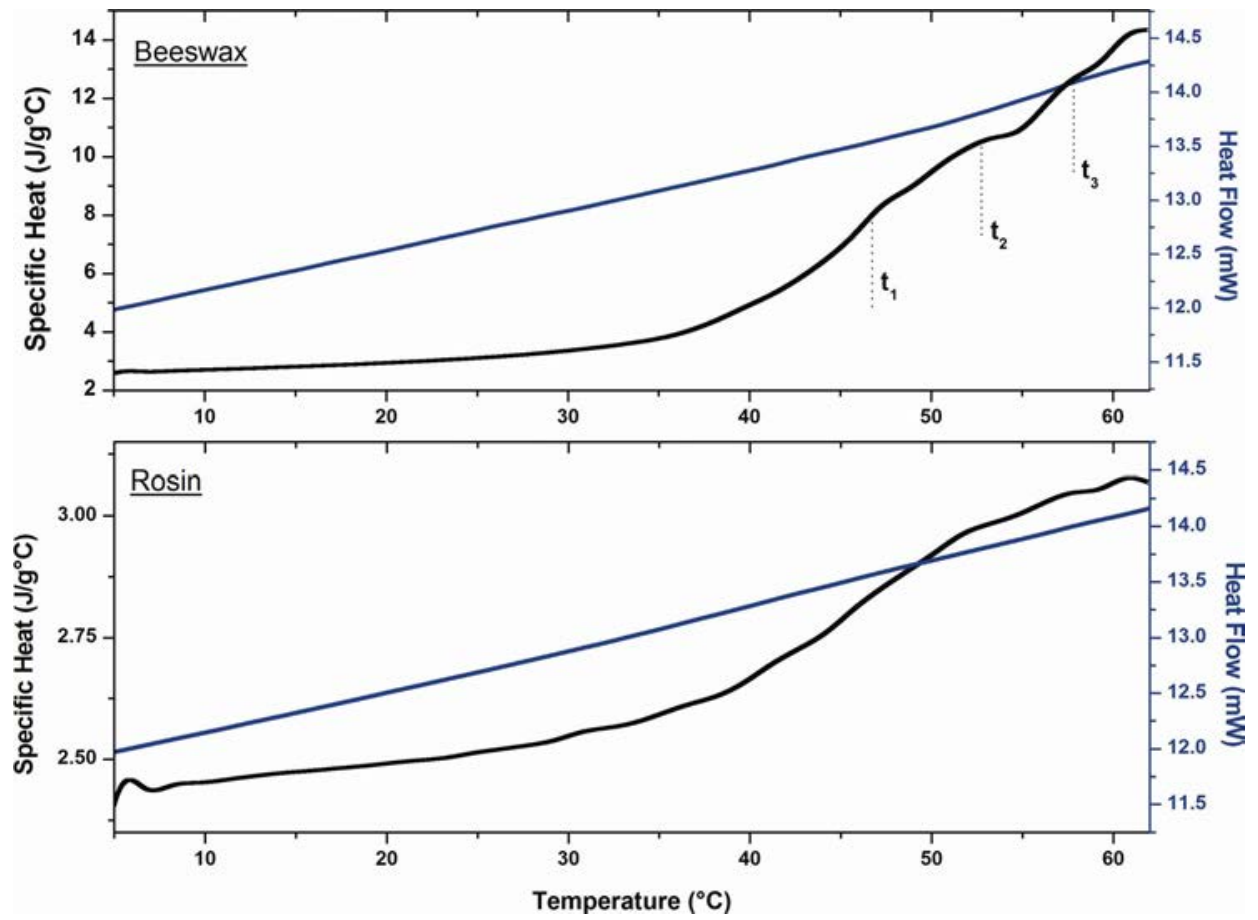

Figure 1. Step-scan DSC thermograms obtained for beeswax and rosin. [Color figure can be viewed in the online issue, which is available at wileyonlinelibrary.com.]

\section{RESULTS AND DISCUSSION}

\section{Microstructure}

Microstructures of the different blends were examined in a previous study. ${ }^{18}$ Beeswax is a partially crystalline material. It crystallizes into a needle-shaped structure. When mixed with rosin, its microstructure evolves, and above all, the size of the needle decreases. Furthermore, for blends containing up to $90 \mathrm{wt} \%$ rosin, the beeswax fraction consists of spherical crystallites uniformly distributed in the matrix. ${ }^{18}$ Pure beeswax exhibits several polymorphic transitions before its melting point at about $65^{\circ} \mathrm{C}$. As studied by DSC, these polymorphic transitions appeared clearly at a rate of $1{ }^{\circ} \mathrm{C} / \mathrm{min} .{ }^{18}$ Figure 1 presents the step-scan DSC thermograms obtained for both beeswax and rosin. In case of beeswax, three polymorphic transitions $\left(t_{1}, t_{2}\right.$, and $\left.t_{3}\right)$ before melting $m$ have been reported in the literature. ${ }^{22-24}$ All of these transitions can be observed on the specific heat curve presented in Figure 1. At the same time, the heat flow curve presented a monotonous increase, which confirmed that these transitions were not glassy ones. With regard to rosin, the variation in the specific heat curve was also observed but around a temperature of $40^{\circ} \mathrm{C}$. The amplitude of this variation was very much smaller compared to the peaks observed in beeswax. Furthermore, as for beeswax, this variation was not accompanied by any sudden change in the heat flow curve. Unlike ambers and aged or commercialized resins, which generally exhibit a glass transition between 20 and $100^{\circ} \mathrm{C},{ }^{20}$ the rosin used here did not exhibit a glass transition.

The same experiment was repeated on a blend of 75 wt \% rosin. As described elsewhere, ${ }^{18}$ the addition of rosin in beeswax plays a key role in the polymorphic transitions and their associ- ated temperatures. Meanwhile, beeswax exhibits three polymorphic transitions in its pristine state during melting; blends containing more than $15 \mathrm{wt} \%$ rosin suffer only two transitions, the $t_{2}$ and $t_{3}$ transitions. Furthermore, the temperatures associated with $t_{2}$ and $t_{3}$ appear to decrease with the content of rosin. The beeswax/rosin phase diagram presented in Gaillard et al. ${ }^{18}$ showed that the temperature of the $t_{2}$ transition varies from $51^{\circ} \mathrm{C}$ for pure beeswax to about $33^{\circ} \mathrm{C}$ for blends containing 90 wt $\%$ rosin. For a $75 \mathrm{wt} \%$ blend, $t_{2}=38.3^{\circ} \mathrm{C}$ and $t_{3}=46.7^{\circ}$ could be deduced. These values were in good accordance with the thermogram given in Figure 2. Additionally, we observed that the blending of beeswax with rosin led to the observation of a $T_{g}$ characterized by an heat capacity jump $\left(\Delta C_{p}\right)$ on the heat flow curve. $T_{g}$ was measured as the inflection point of $\Delta C_{p}$ at a temperature of about $31^{\circ} \mathrm{C}$.

Finally, the microstructure of the blends could be understood as follows. As shown by Gaillard et al., ${ }^{18}$ the blends exhibit a crystalline part uniformly dispersed in the amorphous fraction. The crystals adopt a needle shape, a typical feature of beeswax microstructure. ${ }^{29}$ The amorphous part comprises the rosin and the amorphous fraction of beeswax. The amorphous fraction of beeswax includes the longest carbon chains, that is, the molecules of beeswax, typically polyesters that contain up to 95 carbons. The appearance of a glass transition suggests that amorphous parts of beeswax and rosin are intimately linked.

\section{DMTA}

The following is devoted to the DMTA of the different blends. A $75 \mathrm{wt} \%$ blend was chosen to illustrate the impact of the glass 


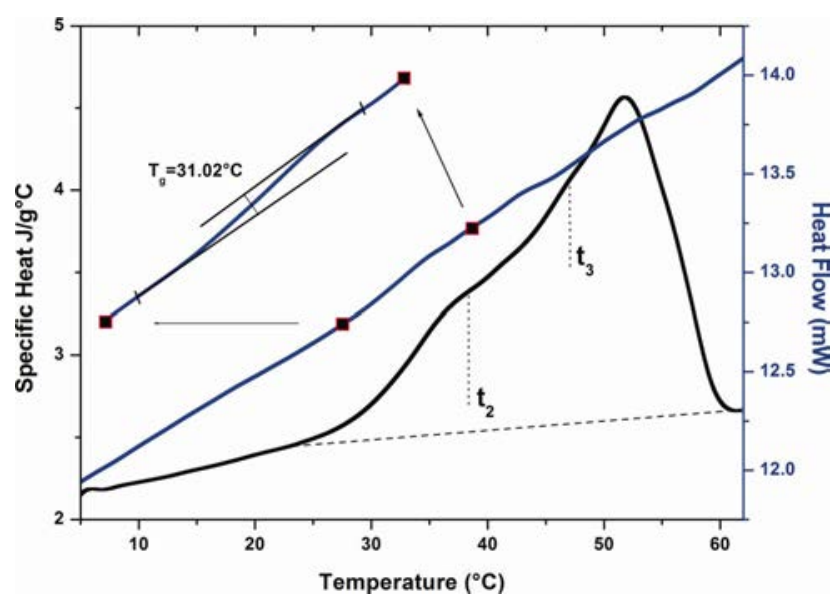

Figure 2. Step-scan DSC thermogram obtained for a blend of $75 \mathrm{wt} \%$ in rosin. $t_{2}$ and $t_{3}$ are the polymorphic transitions of the crystalline part. $T_{g}$ refers to the glass-transition temperature of the amorphous part. [Color figure can be viewed in the online issue, which is available at wileyonlinelibrary.com.]

transition and the polymorphic transition on the mechanical properties. Figure 3 presents the evolution of the $E^{\prime}$, phase, tan $\delta$, and strain rate sensitivity determined by DMTA $\left(m_{\text {DMTA }}\right)$ as a function of the temperature. For convenience, the temperature associated with the glass transition, and the transitions $t_{2}$ and $t_{3}$ of this blend are also indicated on Figure 3. The evolution of the calculated $m$ was very similar to that of $\tan \delta$ measured experimentally.

Typically, we can describe the evolution with the temperature of the thermomechanical response of this blend in the elastic deformation range in the following manner. By DSC (Figure 2), $T_{g}$ was measured at $31^{\circ} \mathrm{C}$, the $t_{2}$ transition was measured at about $38^{\circ} \mathrm{C}$, and the $t_{3}$ transition was measured at about $46^{\circ} \mathrm{C}$. The complete process, glass transition, polymorphic transition, and melting, started at about $24^{\circ} \mathrm{C}$ and finished at $60^{\circ} \mathrm{C}$. Mechanically, the first increase in $\tan \delta$ and $m_{\text {DMTA }}$ was detected between 12 and $35^{\circ} \mathrm{C}$. In this range of temperature, two distinct phenomena occurred: first, the glass transition of the blend located at $31^{\circ} \mathrm{C}$ and, second, the $t_{2}$ transition centered at $38^{\circ} \mathrm{C}$, that is, above $35^{\circ} \mathrm{C}$, but starting at about $24^{\circ} \mathrm{C}$, as shown on Figure 2. So, mechanically, it appeared to be difficult to deconvolute $T_{g}$ from $t_{2}$. Even so, these two transitions resulted in a single increase in $\tan \delta$ and $m_{\mathrm{DMTA}}$. A second increase in $m_{\text {DMTA }}$ was observed from a temperature of about $40^{\circ} \mathrm{C}$ and coincided with the $t_{3}$ transition. According to Kameda, ${ }^{22,24}$ the polymorphic transitions in beeswax are also accompanied by a mobility in the conformational transformations from a transgauche to a trans-trans conformation. This trans-trans conformation corresponds to molecular disentanglement and so can be considered the $\alpha$ relaxation of the beeswax fraction contained in the blends.

It was interesting to note that even at RT $\left(\mathrm{RT}=20^{\circ} \mathrm{C}\right), m$ was clearly influenced by $T_{g}$ and the $t_{2}$ transition, even when these transitions took place at 31 and $38^{\circ} \mathrm{C}$, respectively. This influence grew as well as the $t_{2}$ transition was close to the RT, that is, as well as the proportion of rosin contained in the blend was going to increase. So, in this way, $m$ should have increased with the content of rosin.

\section{Superplastic Behavior}

Compression and shear tests were performed on all of the blends. Figure 4 presents the typical stress-strain curves obtained in compression for the $30 \mathrm{wt} \%$ blend and for shear tests on the $80 \mathrm{wt} \%$ blend. The compression tests presented in Figure 4 (a) were realized at constant strain rate of $9.4 \times 10^{-4}$, $4.5 \times 10^{-3}, 8.6 \times 10^{-3}, 4.4 \times 10^{-2}$, and $8.1 \times 10^{-2} \mathrm{~s}^{-1}$. The

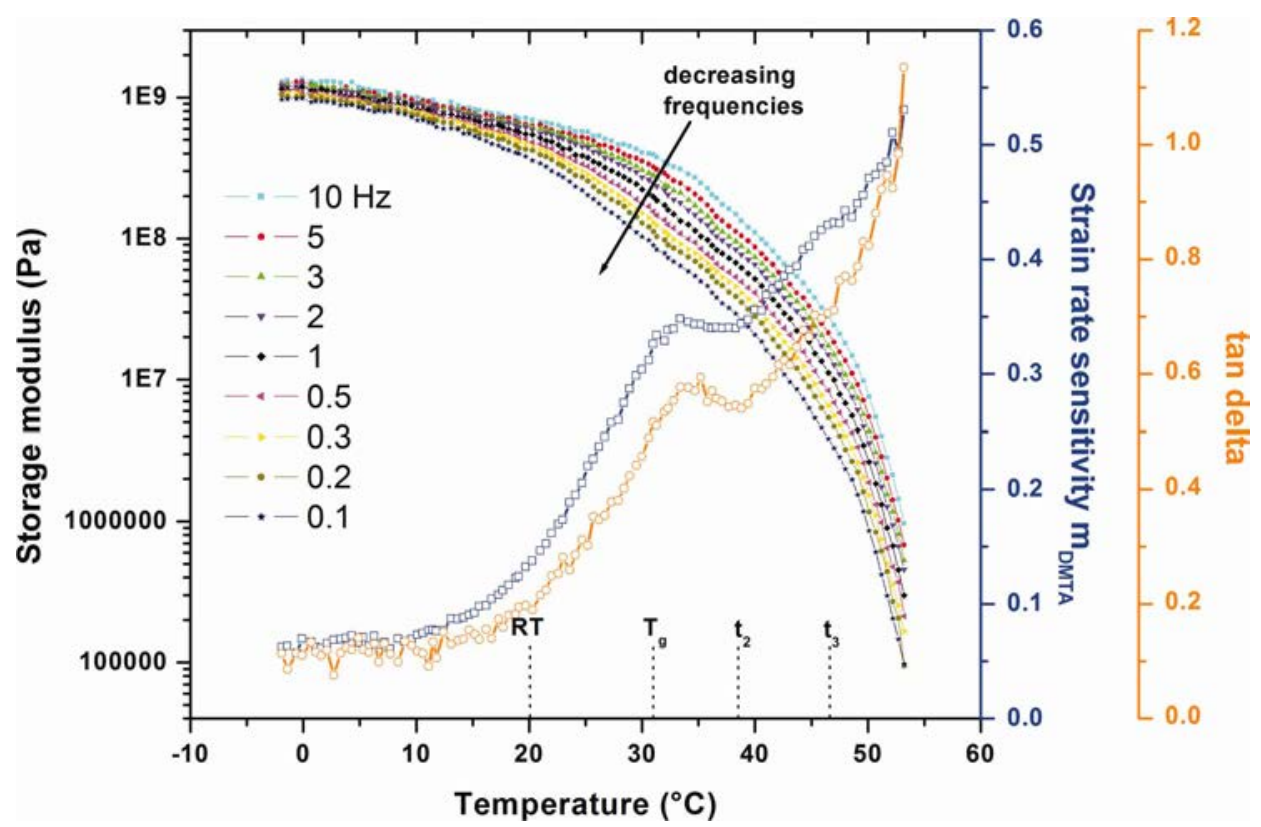

Figure 3. $E^{\prime}, \tan \delta$, and $m_{\mathrm{DMTA}}$ obtained by DMTA in compression in the $75 \mathrm{wt} \%$ blend. [Color figure can be viewed in the online issue, which is available at wileyonlinelibrary.com.] 

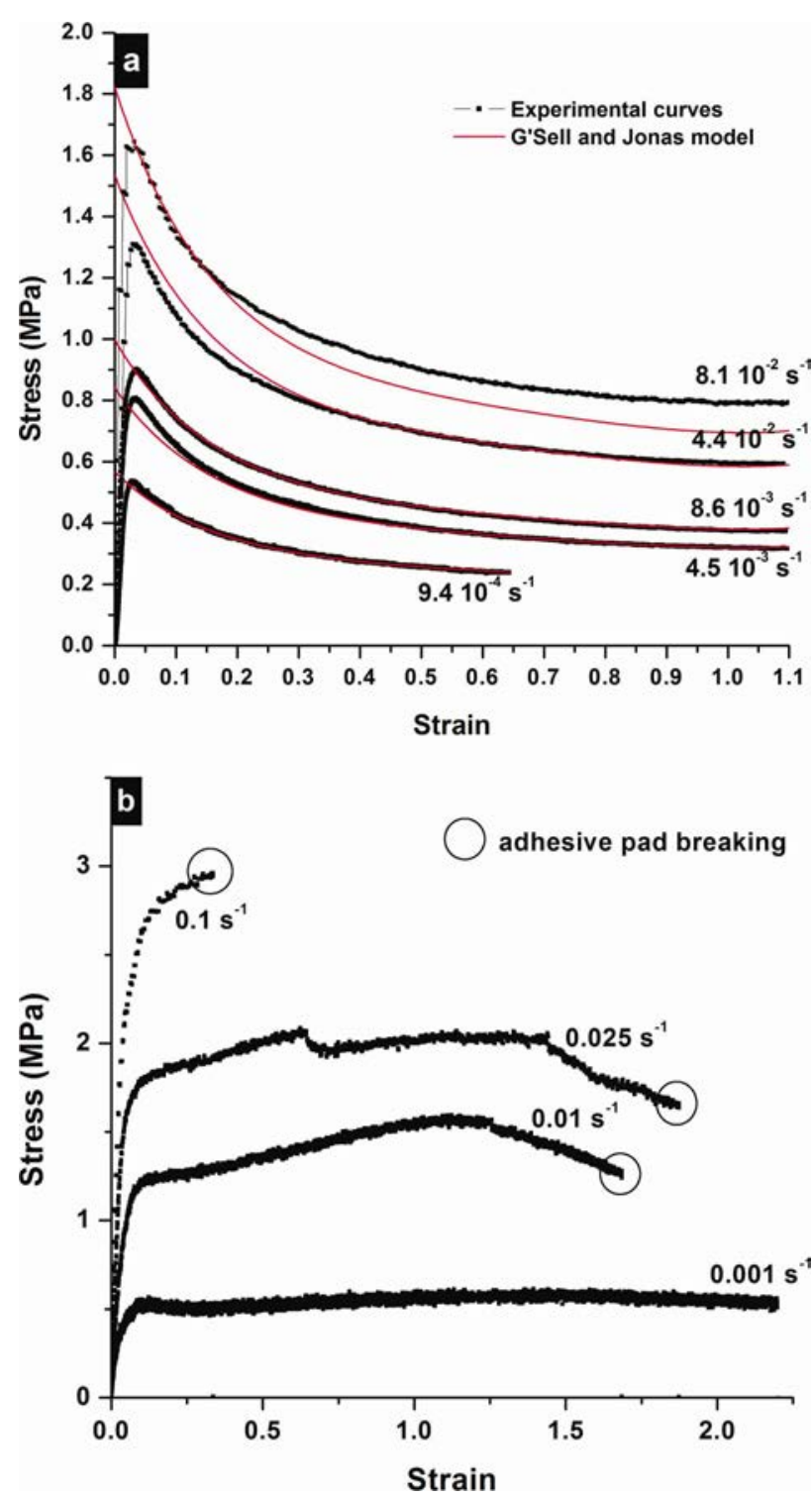

Figure 4. Stress-strain curves obtained (a) in compression mode for the $30 \mathrm{wt} \%$ blend and (b) in shear mode for the $80 \mathrm{wt} \%$ blend. [Color figure can be viewed in the online issue, which is available at wileyonlinelibrary.com.]

experimental compression curves are superimposed with the fit of the G'Sell-Jonas law obtained from eq. (4). From the experimental curves, an $m$ of $0.24 \pm 0.01$ was deduced from eq. (5). Furthermore, for the $30 \mathrm{wt} \%$ blend, the strain-softening characteristics of the mechanical behavior of beeswax ${ }^{30}$ were observed. This softening persisted up to a rosin percentage of 70 wt \%. For higher contents of rosin, both the shear and compression tests exhibited a strain-hardening behavior, as shown on Figure 4(b).

Nanoindentation tests were performed on a 75 wt \% specimen and on pristine rosin as a reference. Figure 5(a) presents the force-penetration curves obtained on the $75 \mathrm{wt} \%$ blend for different constant values of $\dot{h} / h$ : 4, 0.4, 0.04, and $0.004 \mathrm{~s}^{-1}$. In particular, the unloading curve revealed a viscoplastic behavior characterized by the nose effect observed above all at a high deformation rate; ${ }^{29}$ this revealed that the sample was still plastically deformed, whereas the load was withdrawn. This nose effect can be avoided by interposition between loading and unloading of a break of several seconds by the holding of a constant force. ${ }^{31}$ Furthermore, the adhesion between the indenter and the beeswax/rosin blends led to the measurement of negative forces at the end of the unloading segment. This type of curve is characteristic of indentation on adhesive material. ${ }^{32,33}$ The amplitude of this adhesive force is directly related to the surface of the contact between the tip and the sample when the maximum load is reached.

The obtained indentation curves clearly indicated a high $m$, which was evaluated to $0.39 \pm 0.03$ with eq. (6). With pristine rosin, the indentation curves shown in Figure 5(b) exhibited
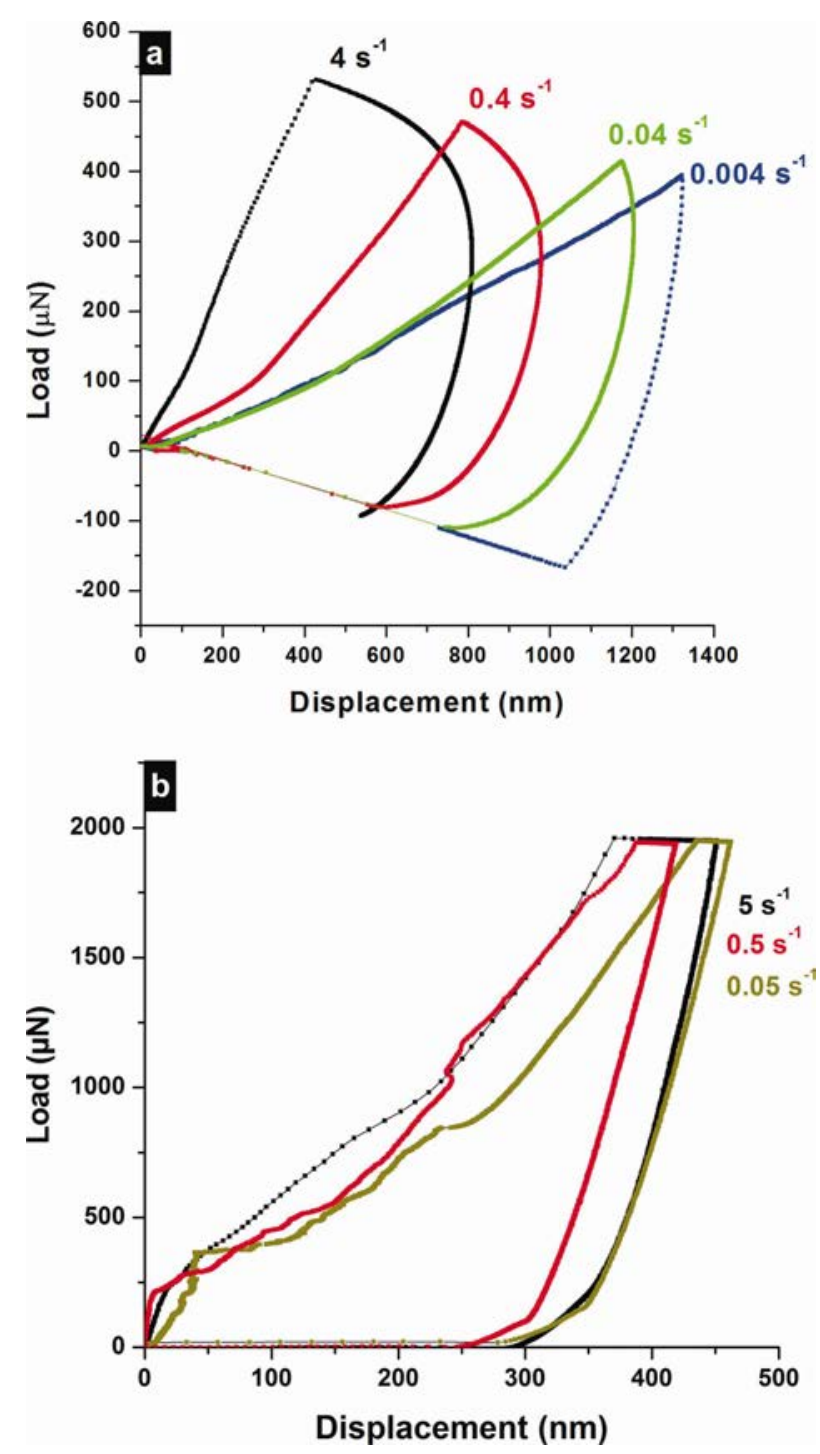

Figure 5. Nanoindentation curves obtained (a) for the 75 wt $\%$ for $\dot{h} / h$ values equal to $4,0.4,0.04$, and $0.004 \mathrm{~s}^{-1}$ and (b) on pristine rosin for $\dot{h} / h$ values equal to $5,0.5$, and $0.05 \mathrm{~s}^{-1}$. [Color figure can be viewed in the online issue, which is available at wileyonlinelibrary.com.] 


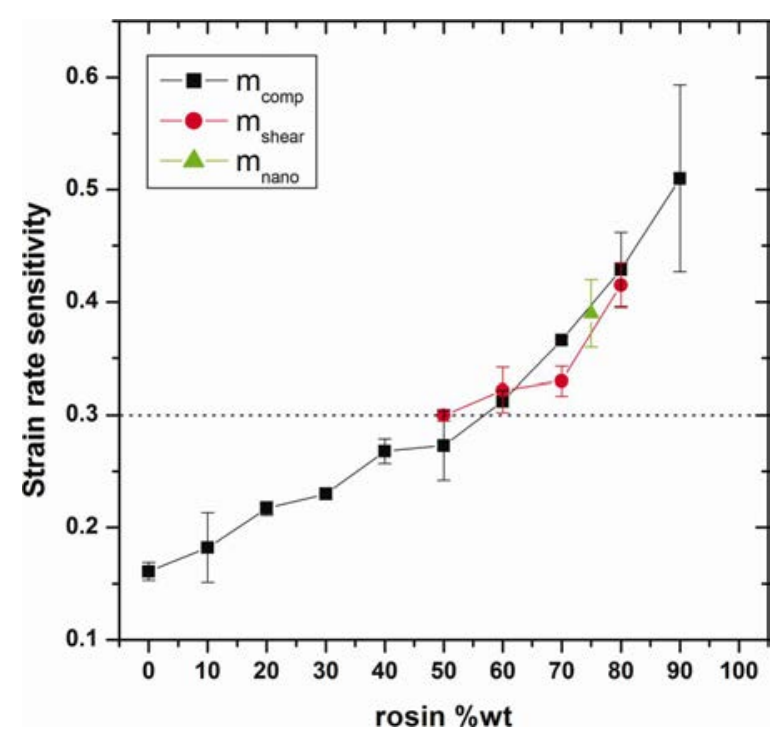

Figure 6. $m$ as a function of the rosin content obtained from the compression $\left(m_{\text {comp }}\right)$, shear $\left(m_{\text {shear }}\right)$, and nanoindentation $\left(m_{\text {nano }}\right)$ tests. [Color figure can be viewed in the online issue, which is available at wileyonlinelibrary.com.]

multiple pop-in events characteristic of very brittle behavior but, above all, did not show any strain rate dependency.

Finally, $m$ was calculated for each mechanical test, as indicated in the Experimental section. The values are summarized in Figure 6. The one obtained by nanoindentation for the $75 \mathrm{wt} \%$ blend appeared to be completely in accordance with the ones obtained by compression and shear. $m$ increased with the rosin contained in the blend until a value of 0.5 was reached. According to Blandin and Suery, ${ }^{34}$ the mechanical behavior of the blends could be considered as superplastic for any value of $m$ greater than 0.3 , that is, for a rosin content up to $60 \mathrm{wt} \%$.

\section{CONCLUSIONS}

Blends of rosin and beeswax formed a partially crystalline material. When the crystalline part was only due to beeswax, the amorphous part was a close blend of rosin and the amorphous part of beeswax. Both the amorphous and crystalline parts were decoupled in step-scan DSC. This meant that the thermograms exhibited both a glass transition and the $\alpha$ relaxation of beeswax, and this conclusion was confirmed by DMTA measurements.

The $m$ value at RT in the elastic but also in the plastic regime appeared to be greatly influenced by the glass transition but also by the first phase transition of the crystalline part of the blends, themselves dependent on the rosin content. Although in their pristine state, beeswax and rosin are two materials in which elastic/plastic regimes do not exhibit high $m$ at RT, the blend of rosin and beeswax are more prone to viscous behavior.

In particular, the viscoplastic behavior reached the superplastic regime for blends with more than $60 \mathrm{wt} \%$ rosin. It was interesting to note that the addition of only $10 \%$ plasticizer was enough to enhance the superplastic regime of the rosin. New perspectives for the design of complex shapes may be exploited thanks to this superplastic behavior. The mechanical reliability of these adhesives based on rosin will then be largely improved.

Finally, the use of several mechanical tests combined with DSC and DMTA measurements allowed us to fully understand the behavior of the different blends. Indeed, the complex plastic behavior of the pristine rosin cannot be studied with only classic mechanical testing. Only the solicitation of the sample under high confining pressures, as reached in nanoindentation, allowed us to plastically deform rosin at RT. The results given by the different techniques were in good accordance and clearly confirmed the superplastic behavior of the beeswax/rosin blends at RT.

\section{ACKNOWLEDGMENTS}

The authors thank Alice Mija and Nicolas Sbirrazzuoli from the University of Nice, Sophia Antipolis, for fruitful discussions about the DSC thermograms.

\section{REFERENCES}

1. Maiti, S.; Sinha Ray, S.; Kundu, A. K. Prog. Polym. Sci. 1989, 14, 297.

2. Comin, J. Int. J. Adhes. Adhes. 1995, 15, 9.

3. Candy, L. Ph.D. dissertation, Institut National Polytechnique de Toulouse, 2003.

4. Georgi, E. A. J. Chem. Ed. 1933, July, 415.

5. Pilato, L. Phenolic Resins: A Century of Progress; Springer: Bound Brook NJ, USA, 2010.

6. Baldwin, D. E.; Loeblich, V. M.; Lawrence, R. V. Ind. Eng. Chem. 1958, 3, 342.

7. Vandembroucq, D.; Deschamps, T.; Coussa, C.; Perriot, A.; Barthel, E.; Champagnon, B.; Martinet, C. J. Phys. Cond. Mat. 2008, 20, 485221.

8. Perriot, A.; Martinez, V.; Grosvalet, L.; Martinet, C.; Champagnon, B.; Vandembroucq, D.; Barthel, E. J. Am. Ceram. Soc. 2006, 89, 596.

9. Barton, J.; Guillemet, C.; Le Verre Science et Technologie; EDP Science: Bonchamp-Lès-Laval, France, 2005.

10. Kermouche, G.; Barthel, E.; Vandembroucq, D.; Dubujet, P. Acta Mater. 2008, 56, 3222.

11. Argon, A. S. Acta Metall. 1979, 27, 47.

12. Schuh, C. A.; Hufnagel, T. C.; Ramamurty, U. Acta Mater. 2007, 55, 4067.

13. Gravier, S. Ph.D. dissertation, Institut National Polytechnique de Grenoble, 2006.

14. Perez, J. Matériaux non Cristallins et Science du Désordre; Presses Polytechniques et Universitaires Romandes: Lausanne, Switzerland, 2001.

15. Anuar, H.; Zuraida, A. Compos. B 2011, 42, 462.

16. Kobayashi, T.; Wood, B.; Takemura, A. J. Appl. Polym. Sci. 2011, 119, 2714.

17. Li, J.; Wang, S.; Yang, W.; Xie, B.; Yang, N. J. Appl. Polym. Sci. 2011, 121, 554.

18. Gaillard, Y.; Mija, A.; Burr, A.; Darque-Ceretti, E.; Felder, E.; Sbirrazzuoli, N. Thermochim. Acta 2011, 521, 90. 
19. Leygonie. http://ets-leygonie.net/. Accessed on May 3, 2011.

20. Jablonski, P.; Golloch, A.; Borchard, W. Thermochim. Acta 1998, 333, 87.

21. Lee, C. M.; Lim, S.; Kim, G. Y.; Kim, D.; Kim, D. W.; Lee, H. C.; Lee, K. Y. Biotechnol. Bioprocess. Eng. 2004, 9, 476.

22. Kameda, T. J. Phys. D 2005, 38, 4313.

23. Kotel'nikova, E. N.; Platonova, N. V.; Filatov, S. K. Geol. Ore Deposits 2007, 49, 697.

24. Kameda, T.; Tamada, Y. Int. J. Biol. Macromol. 2009, 44, 64.

25. Pielichowski, K.; Flejtuch, K.; Pielichowski, J. Polymer 2004, 45, 1235.

26. Gunaratne, L. M. W. K.; Shanks, R. A. Eur. Polym. J. 2005, $41,2980$.
27. Papageorgiou, G. Z.; Achilias, D. S.; Karayannidis, G. P.; Bikiaris, D. N.; Roupakias, C.; Litsardakis, G. Eur. Polym. J. 2006, 42, 434.

28. G'Sell, C.; Jonas, J. J. Mater. Sci. 1979, 14, 583.

29. Schoening, F. R. L. South African J. Sci. 1980, 76, 262.

30. Morgan, J.; Townley, S.; Kemble, G.; Smith, R. Mater. Sci. Technol. 2002, 18, 463.

31. Ebenstein, D. M.; Pruitt, L. A. Nanotoday 2006, 1, 26.

32. Giri, M.; Bousfield, D. B.; Unertl, W. N. Langmuir 2001, 17, 2973.

33. Yang, F. J. Phys. D 2002, 35, 2614.

34. Blandin, J.-J.; Suery, M. Technique de l'ingénieur-traité matériaux métalliques 1996, M600. 